8. Naylor, C. D., O'Rourke, K., Detsky, A. S., \& Baker, J. P. Branched-chain amino acids in hepatic encephalopathy (letter). Gastroenterology, 1990, 99, 605-07.

9. Naylor, C. D., O'Rourke, K., Detsky, A. S., \& Baker, J. P. Branched-chain amino acids in hepatic encephalopathy (letter). Gastroenterology, 1990, 99, 1395-96.

\title{
COST-EFFECTIVENESS OF EXTRACORPOREAL SHOCK WAVE LITHOTRIPSY
}

To the Editors:

In Volume 6, Number 4, Hatziandreu, Carlson, Mulley, and Weinstein have written an interesting and useful article on the cost-effectiveness of extracorporeal shock wave lithotripsy (ESWL).

Their observations on per-case costs and sequelae are no doubt valid, but they may miss a most important point in comparing noninvasive therapies to invasive alternatives. When a new procedure is much safer, less traumatic, and less disabling, it will likely be used more frequently than the procedure it replaces. ESWL versus surgical lithotomies is a case in point.

At Blue Cross and Blue Shield of the National Capital Area, we are able to compare the number of open lithotomies we covered in our nonfederal population to the number of ESWL procedures after the new technology became available locally in midyear 1986:

$\begin{array}{ccc} & \text { Lithotomies } & \text { ESWL } \\ \text { procedures }\end{array}$

We have confirmed in discussions with urologic surgeons that ESWL, an essentially painless and safe procedure, made it appropriate to treat a great many patients with kidney stones who would never have been considered for the open surgical procedure. Most stones, after all, eventually pass naturally, albeit very painfully.

Any evaluation of "cost-effectiveness," it seems to me, must look not only at percase data but also at changes in the incidence of therapy. We are spending enormously more for ESWL than we ever did for surgical open lithotomies.

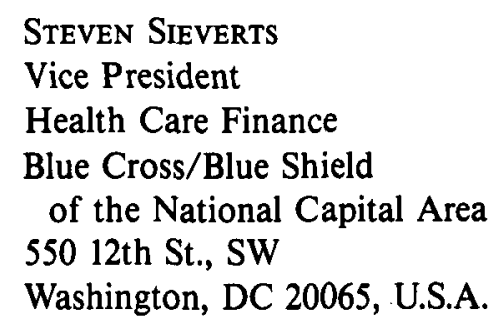

